Supporting Information

\title{
Theoretical and experimental evaluation of the reduction potential of straight chain alcohols for the designed synthesis of bimetallic
}

\section{nanostructures}

Masanao Ishijima ${ }^{\dagger}$, Takatoshi Matsumoto $\ddagger$, Jhon L. Cuya Huaman ${ }^{\dagger}$, Kozo Shinoda

Masahito Uchikoshi ${ }^{\ddagger}$, Kohei Matsuo ${ }^{\dagger}$, Kazumasa Suzuki†, Hiroshi Miyamura ${ }^{\dagger}$, and Jeyadevan Balachandran ${ }^{{ }^{*}}$

Department of Materials Science, The University of Shiga Prefecture, Hikone, Shiga 522-8533, Japan.

Institute of Multidisciplinary Research for Advanced Materials, Tohoku University, Sendai 9808577, Japan.

*Corresponding author

* Jeyadevan Balachandran. Email: jeyadevan.b@mat.usp.ac.jp 
Table S1. Boiling point and heat capacity of each alcohol ${ }^{[1]}$

\begin{tabular}{|c|c|c|c|}
\hline name & B. P. $(\mathrm{K})$ & B. P. $\left({ }^{\circ} \mathrm{C}\right)$ & Specific heat $(\mathrm{J} / \mathrm{mol} \cdot \mathrm{K})$ \\
\hline methyl alcohol & 337.65 & 64.50 & 81.32 \\
\hline ethanol & 352.20 & 79.05 & 112.26 \\
\hline 1-propanol & 370.30 & 97.15 & 144.60 \\
\hline 1-butanol & 390.77 & 117.62 & 209.12 \\
\hline 1-pentanol & 410.90 & 137.75 & 244.80 \\
\hline 1-hexanol & 429.70 & 156.55 & 274.10 \\
\hline 1-heptanol & 449.50 & 176.35 & 324.00 \\
\hline 1-octanol & 469.20 & 196.05 & 330.10 \\
\hline 2-heptanol & 453.20 & 180.05 & 338.50 \\
\hline 3-heptanol & 474.00 & 200.85 & 337.60 \\
\hline 4-heptanol & 474.18 & 201.03 & 330.10 \\
\hline 2-octanol & 453.20 & 180.05 & 338.50 \\
\hline 3-octanol & 474.00 & 200.85 & 337.60 \\
\hline 4-octanol & 474.18 & 201.03 & \\
\hline
\end{tabular}

[1] Céondo GmbH, 2014-2016. Physical and Chemical Property Prediction, Experimental Properties \& Databases, https://www.chemeo.com/ (2021.1.6)

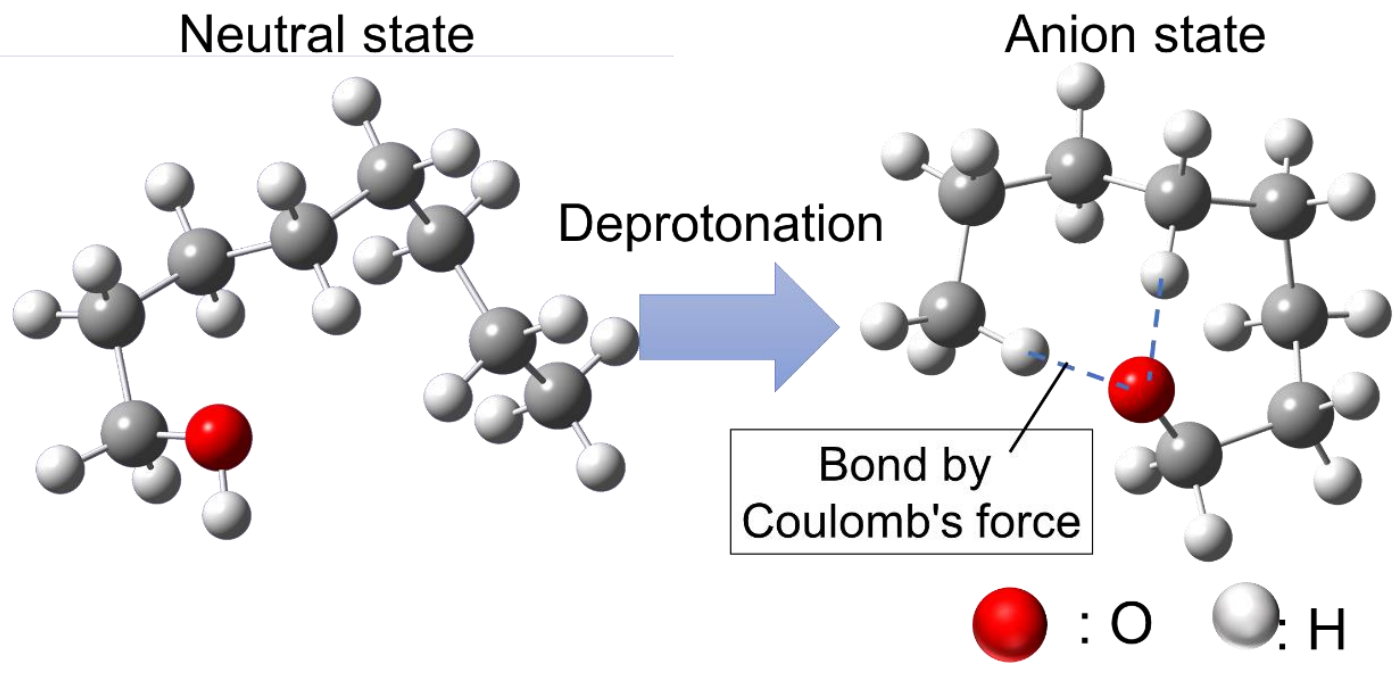

Figure S1. Deprotonation of neutral state of 1-octanol to anion state at room temperature. The $\mathrm{O}^{-}$moiety, which is the active site, is covered by the molecular chain. 
(a)

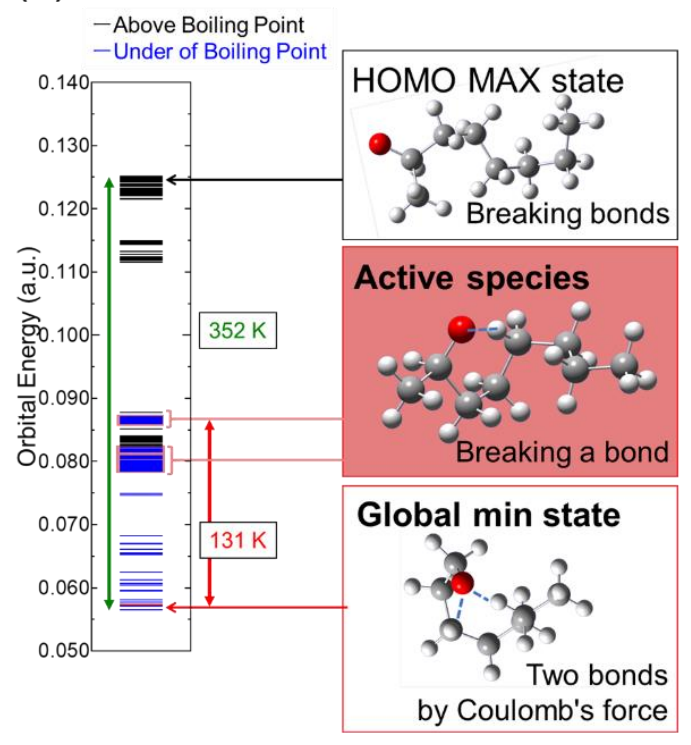

(b)

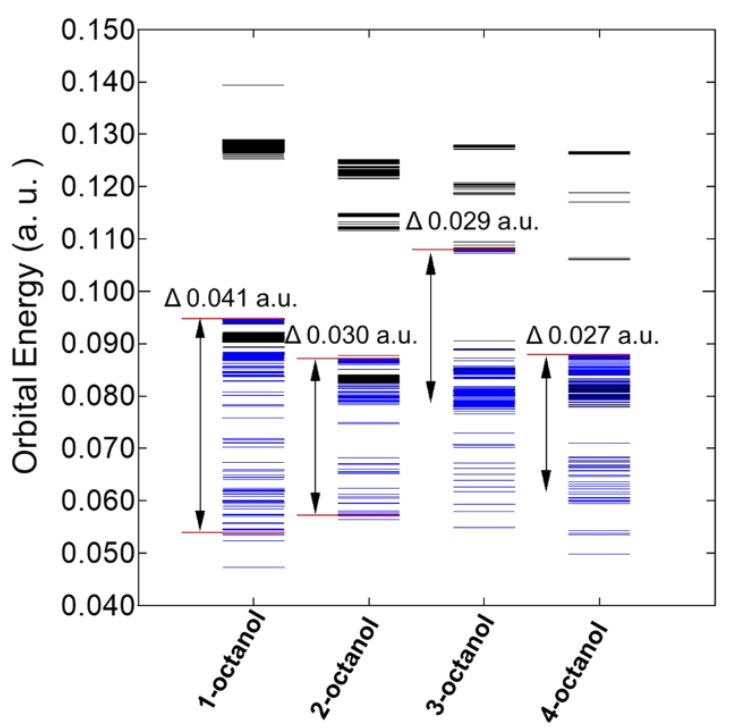

Figure S2 (a) Fingerprint and molecular structures of 2-octanol at each energy levels and (b) fingerprint of secondary alcohols in the anion state. 1-octanol has the lowest global minimum value (0.054 a.u.), followed by 2-octanol (0.057 a.u.), 4-octanol (0.061 a.u.), and 3-octanol (0.079 a.u.).

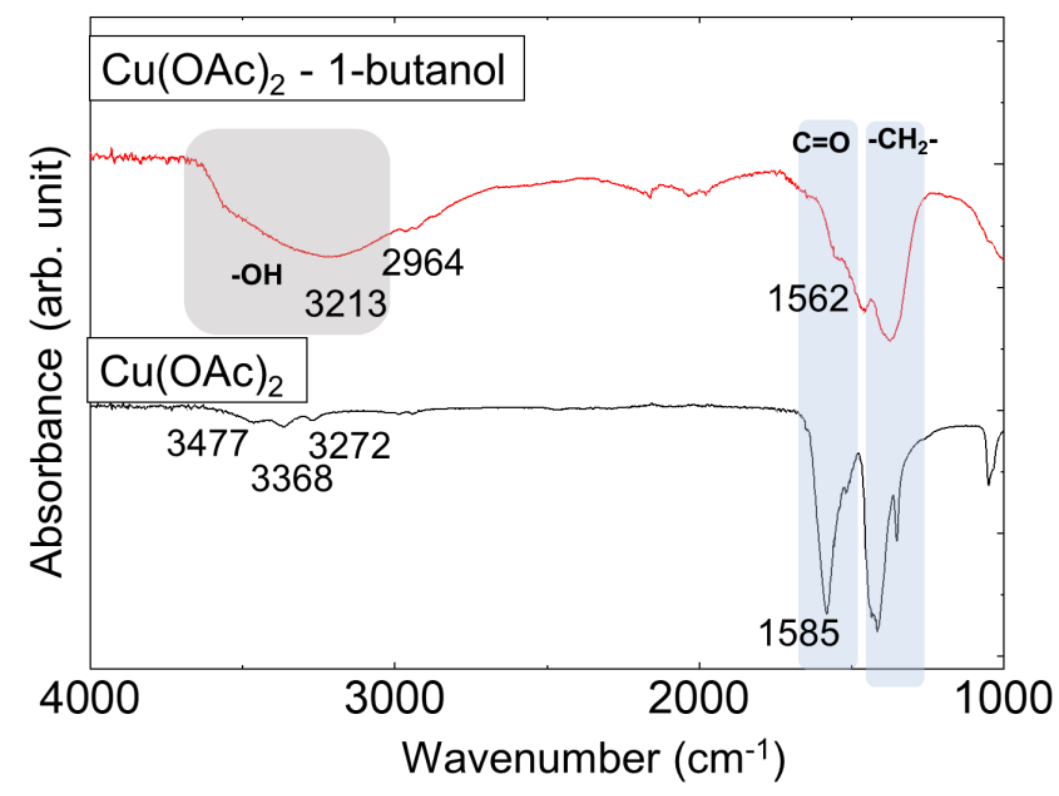

Figure S3. FT-IR spectra of the sediment obtained in $\mathrm{Cu}$ acetate - 1-butanol system and $\mathrm{Cu}$ acetate precursor. 
Table S2. The partic le and crystallite sizes of metal partic les synthesized in alcohols.

\begin{tabular}{|c|c|c|c|c|}
\hline Metal & Alcohol & Particle size (nm) & Crystallite size (nm) & Phase \\
\hline \multirow{3}{*}{$\mathrm{Cu}$} & 1-hexanol & 362 & 78.0 & $\mathrm{Cu}$ \\
\cline { 2 - 5 } & 1-heptanol & 280 & 58.2 & $\mathrm{Cu}$ \\
\cline { 2 - 5 } & 1-octanol & 133 & 50.2 & $\mathrm{Cu}$ \\
\hline \multirow{3}{*}{$\mathrm{Ni}$} & 1-pentanol & 593 & 42.1 & intermediate + Ni \\
\cline { 2 - 5 } & 1-hexanol & 687 & 43.2 & $\mathrm{Ni}$ \\
\cline { 2 - 5 } & 1-heptanol & 729 & 44.4 & $\mathrm{Ni}$ \\
\cline { 2 - 5 } & 1-octanol & 185 & 36.8 & $\mathrm{CoO}$ \\
\hline \multirow{3}{*}{$\mathrm{Co}$} & 1-hexanol & 78 & 7.0 & $\mathrm{CoO}+\mathrm{Co}(\mathrm{hcp})$ \\
\cline { 2 - 5 } & 1-heptanol & 42 & 23.4 & $\mathrm{Co}$ \\
\cline { 2 - 5 } & 1-octanol & 259 & 20.7 & \\
\hline
\end{tabular}
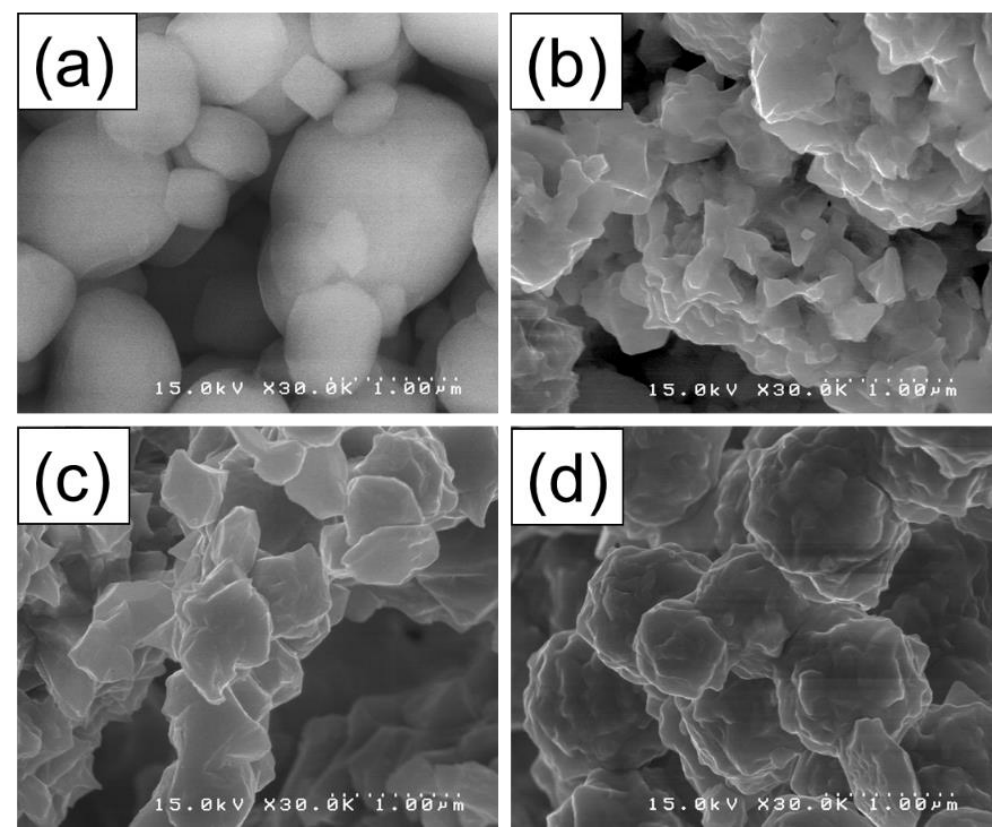

Figure S4. FE-SEM images of sediments obtained using Ni acetate tetrahydrate in (a)1-butanol, (b) 1-pentanol, (c) 1-hexanol, and (d) 1-heptanol. 


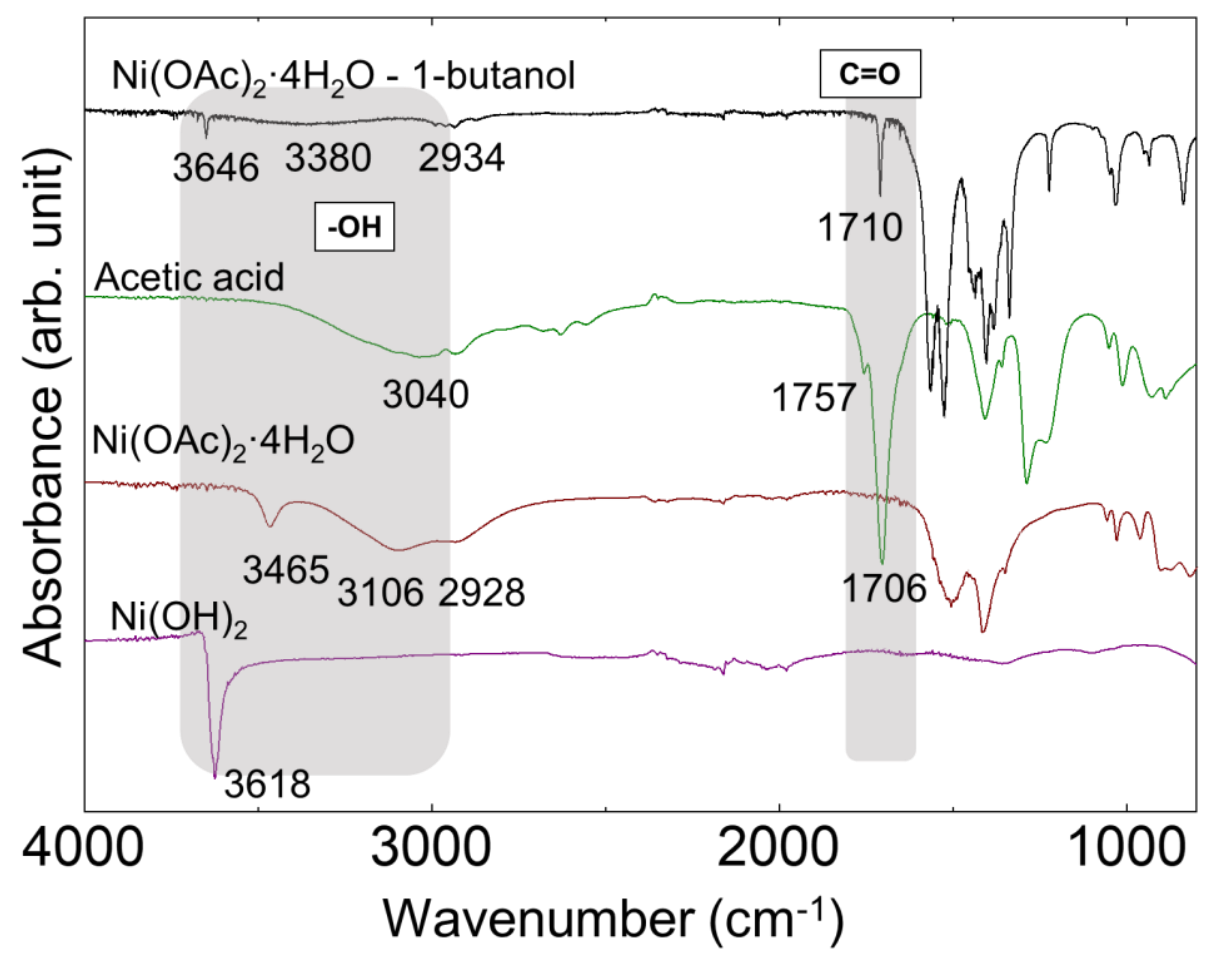

Figure S5. FT-IR spectra of the sediments obtained in Ni acetate-1-butanol system, acetic acid, Ni ac etate tetrahydrate, and Ni hydroxide.
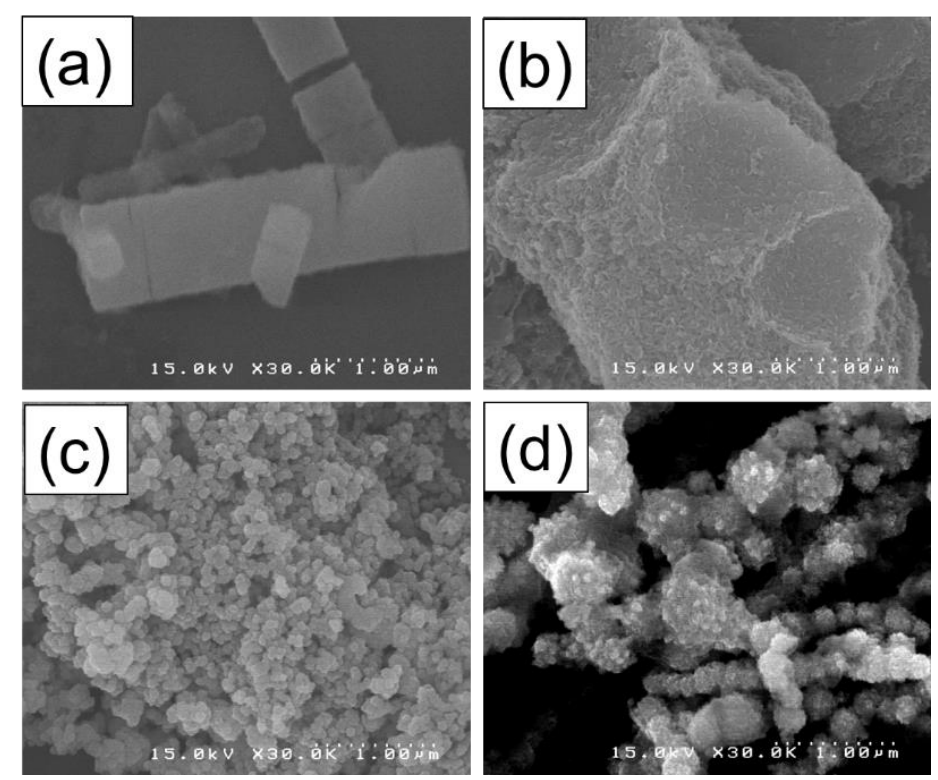

Figure S6. FE-SEM images of sediments obtained using Co-acetate tetrahydrate in (a)1-butanol, (b) 1-pentanol, (c) 1-hexanol, and (d) 1-heptanol. 

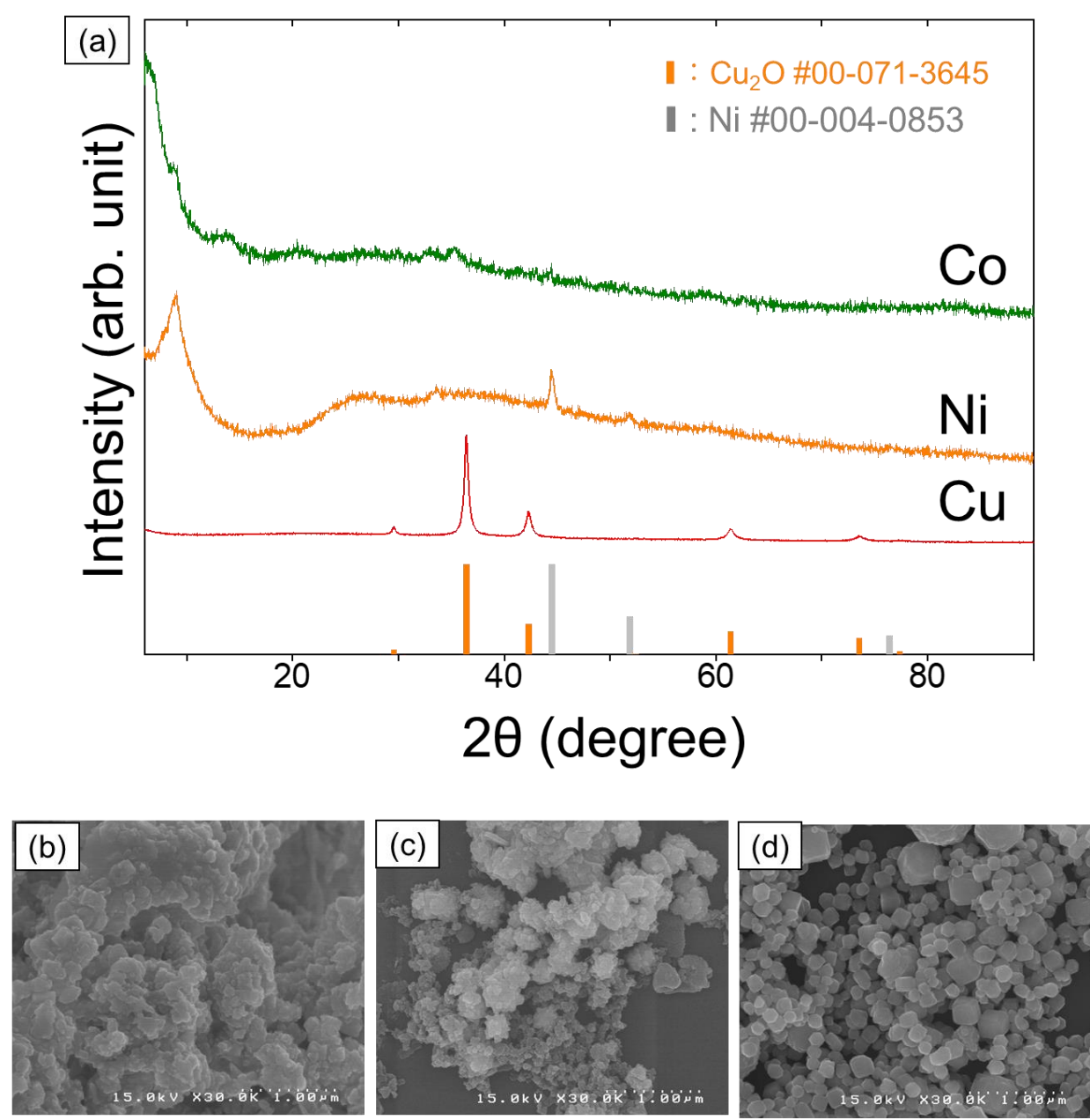

Figure S7. (a) XRD patterns and FE-SEM images of the sediments obtained in 2-octanolusing (b) cobalt acetate, (c) nickel acetate, (d) copper acetate as precursors. 
(a)

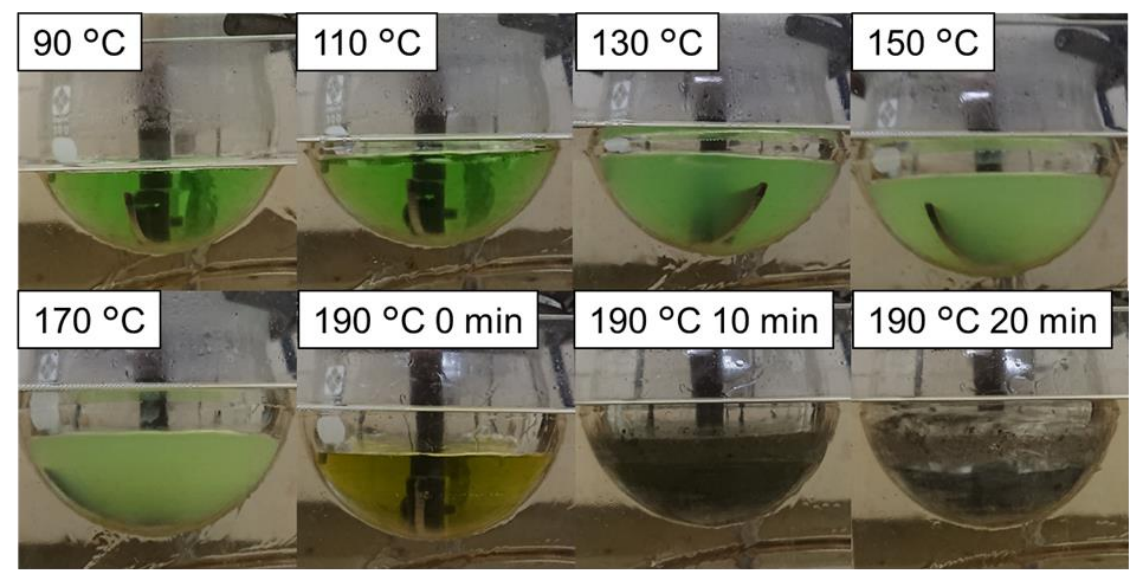

(b)

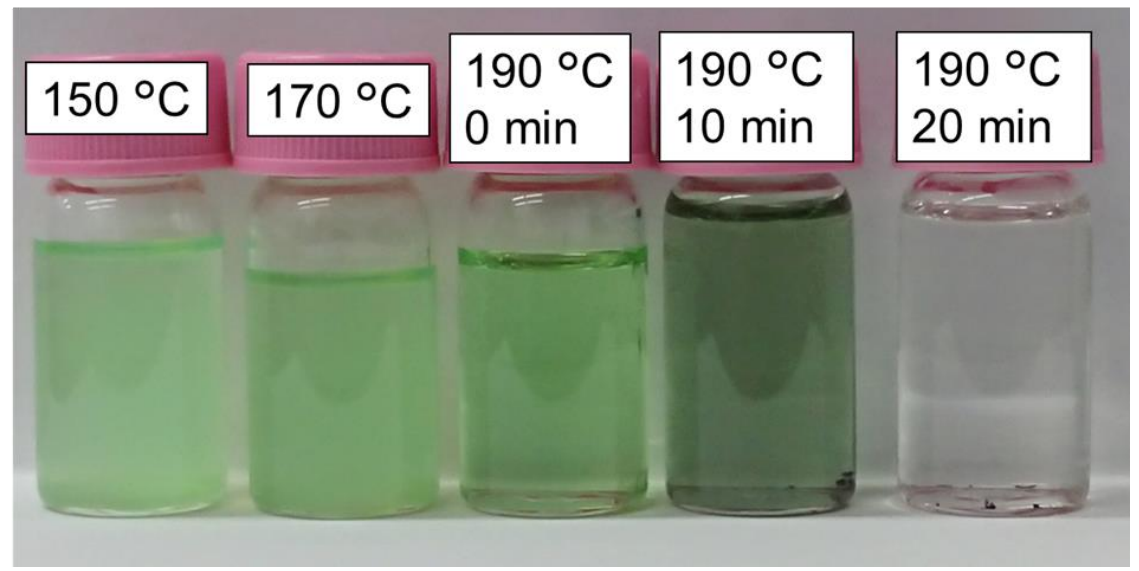

Figure S8. (a) Photographs of the solution at different temperatures and reaction times during the synthesis of $\mathrm{Ni}$ in 1-octanol, and (b) sampled solution at R.T. 


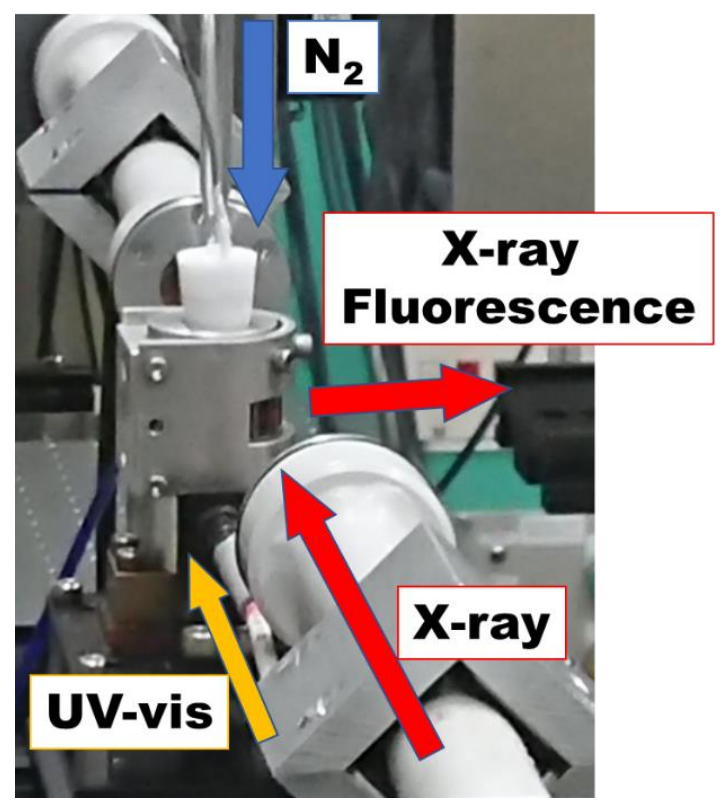

Figure S9. Schematic illustration of the in-situ XAFS and UV-vis measurement system.

(a)
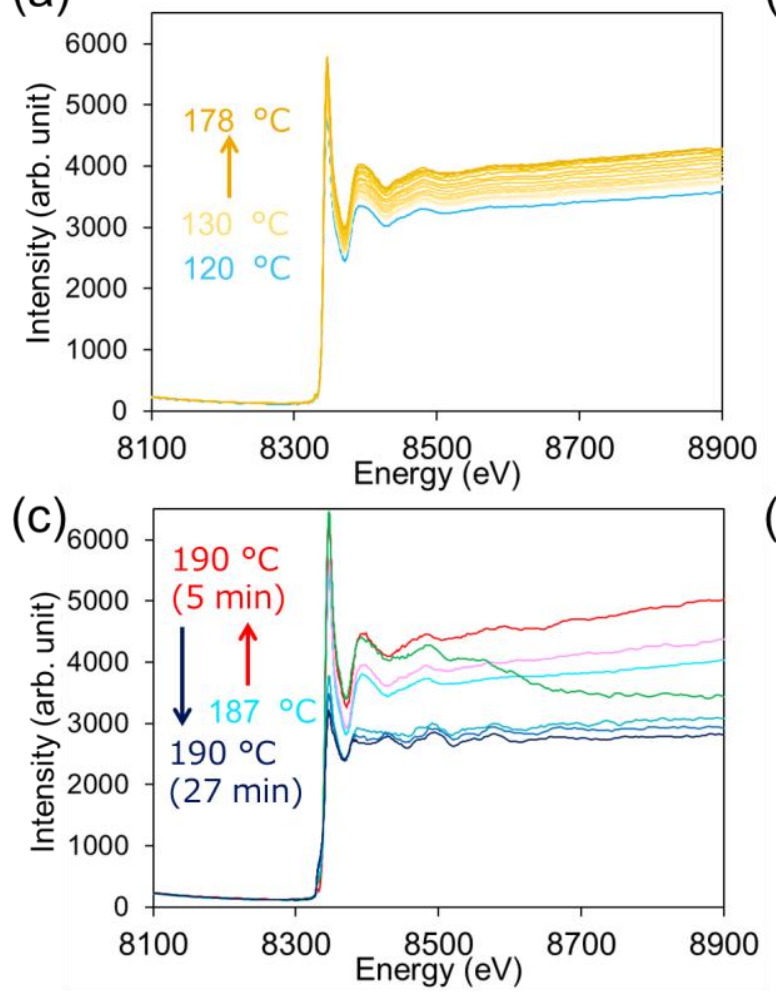

(b)

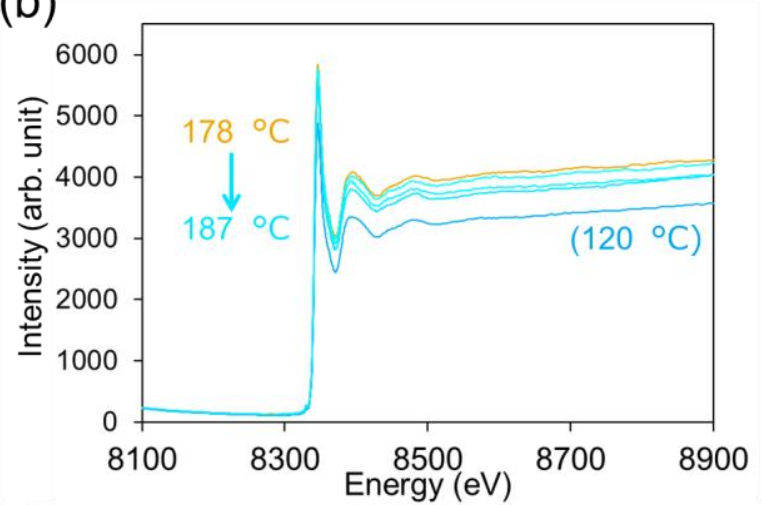

(d)

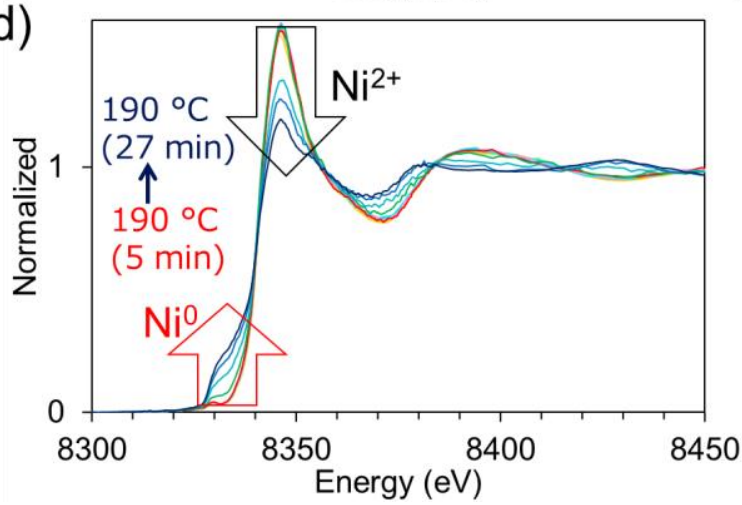

Figure S10. The in-situ XAFS spectra measured each temperature (a) $120-178{ }^{\circ} \mathrm{C}$, (b) $178-187^{\circ} \mathrm{C}$, (c) 187 $190^{\circ} \mathrm{C}$ and (d) XANES spectra of each temperature. 


\section{STEP 1}

Coordination exchanges

Elimination of acetate anion

(esterification)

STEP 2

Formation of alkoxide

\section{STEP 3}

Reduction of metal cation
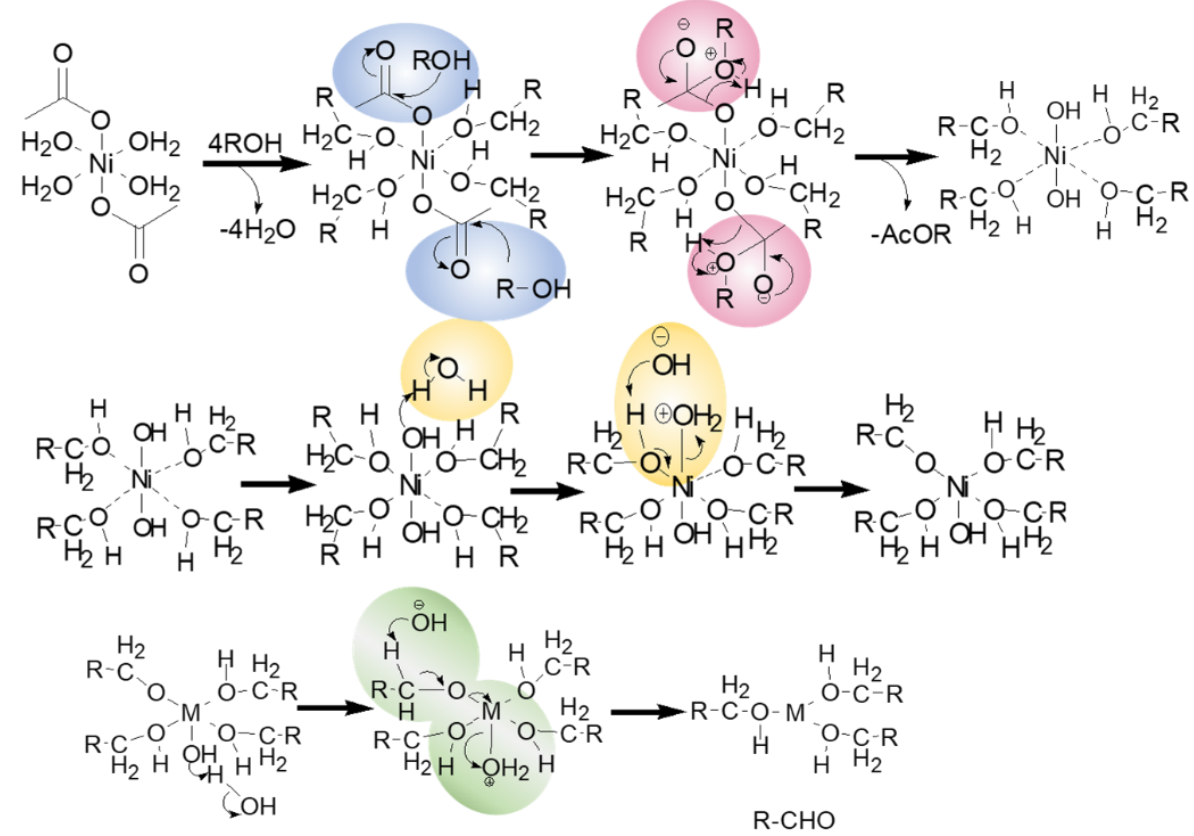

Figure S11. Detail of the proposed reaction mechanism in alcohol reduction method.
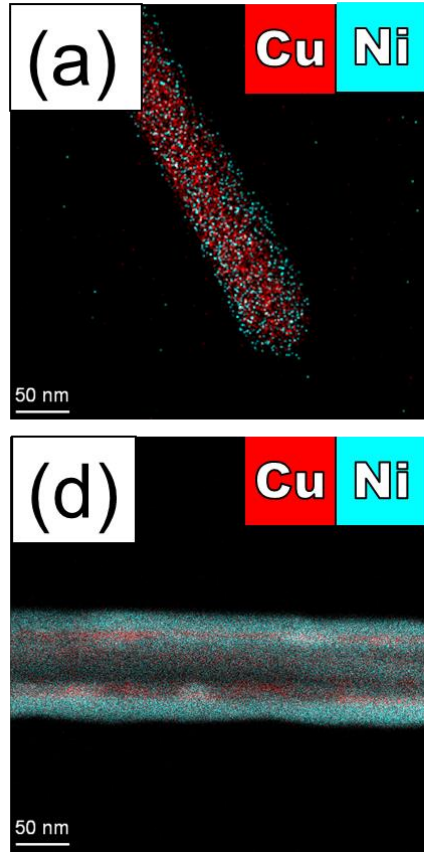
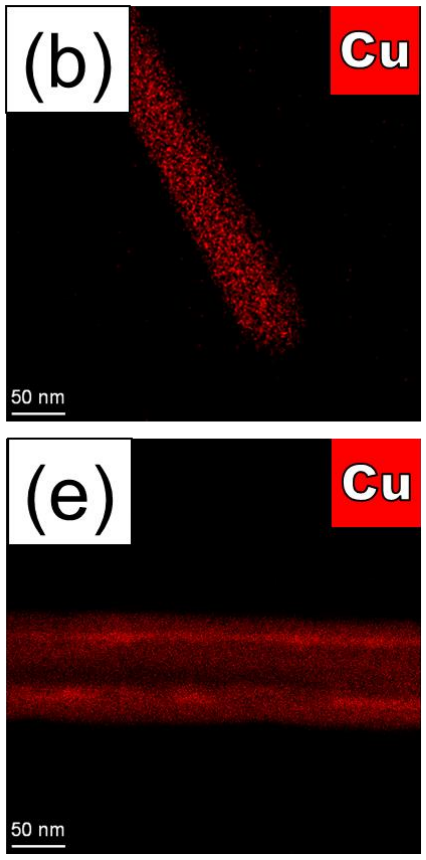
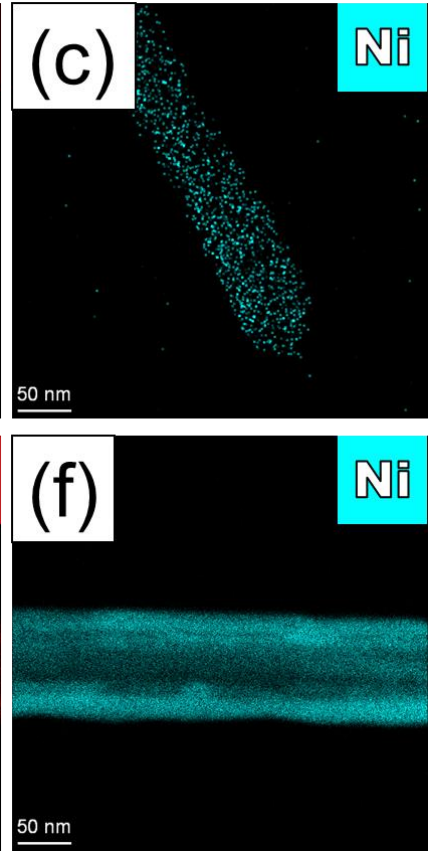

Figure S12. EDS mapping images of time resolved products obtained for a reflux time of (a)-(c) $3.5 \mathrm{~h}$ and (d)-(f) $5.0 \mathrm{~h}$ at $190{ }^{\circ} \mathrm{C}$ during synthesis $\mathrm{Cu}-\mathrm{Ni}$ nanotubes. 